
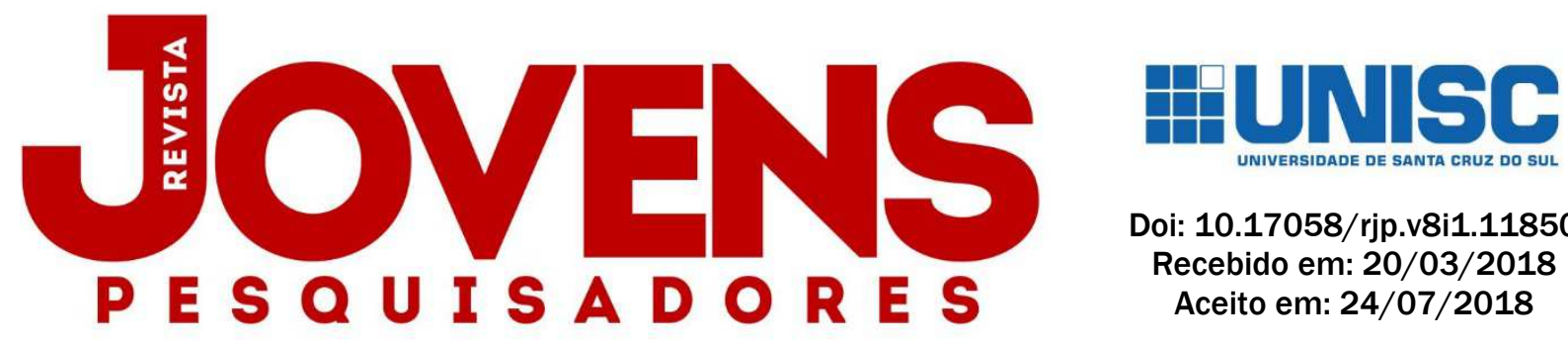

Doi: $10.17058 /$ rjp.v8i1.11850

Recebido em: 20/03/2018

Aceito em: 24/07/2018

\title{
NARRATIVA AUTOFICCIONAL EM A RESISTÊNCIA: INTERSECÇÕES ENTRE O REAL E O FICCIONAL
}

\author{
RIEGER, N. P.1; MELLO, G. D.1; DOMINGOS, A. C. M.² \\ PALAVRAS CHAVE: Literatura contemporânea. Autoficção. Julián Fuks. Narrador.
}

\section{RESUMO}

0 presente trabalho se vincula ao projeto Vozes da cultura contemporânea 2: o narrador na cultura da conexão, orientado pela Prof. ${ }^{a}$ Dr. $^{a}$ Ana Cláudia Munari, o qual objetiva analisar a produção ficcional contemporânea a fim de encontrar tendências que se relacionem a novas práticas de leitura e escrita. Neste trabalho, nosso objeto é uma dessas tendências, a autoficção. A narrativa autoficcional pode ser observada em duas formas de ocorrência: quando os relatos de vivência do narrador se assemelham à biografia do autor empírico, ou nos trechos em que o narrador simula o processo de escrita (KLINGER, 2012). Para compreender essa presença autoficcional, o presente trabalho analisa $A$ resistência (2015), de Julián Fuks. Na obra há, entre o autor e o narrador, uma aproximação íntima, uma mistura entre as experiências de um e a narrativa do outro. Ali, assistimos a um jogo performático no qual o narrador-protagonista assume estar escrevendo um livro, encenando seu processo de escritura para aquele que o lê. As revelações do próprio autor sobre a inserção de fatos reais no livro e a performance da escrita evidenciam uma conexão intrínseca entre a vida de Fuks e seu narrador. É nas confluências entre o real e o ficcional que focalizamos nossa análise.

\section{SELF-FICTIONAL NARRATIVE IN THE RESISTANCE: INTERSECTIONS BETWEEN REAL AND FICTIONAL}

\author{
KEYWORDS: Contemporary literature. Autoficcion. Julián Fuks. Narrator.
}

\begin{abstract}
The present work is linked to the project Voices of the contemporary culture 2: the narrator in the connection culture, guided by Prof. Dr. Ana Cláudia Munari. It aims to analyze the contemporary fictional production in order to find tendencies that relate to the new reading and writing practices. We understand that cultural practices emanate the autofiction in the literature field. An autoficcional narrative can be found in two ways on the text: when the narrator's narrative experiences resemble to the biography of the empirical author, or in the passages in which the narrator simulates its writing process (KLINGER, 2012). Looking at the simulation of these autofictional subjects, this paper analyzes The Resistance (2015), by Julián Fuks. In this work it is clear, between the author and the narrator, that there is an intimate approximation, an access between the experiences of one and the experiences of the other. Still, we witness a performance game in which the narrator-protagonist assumes that he is writing a book, performing his writing process for his readers. The author's own revelations about the insertion of actual facts in the book and the performance of the writing evidence an intrinsic connection between the life of Fuks and his narrator. It is at the confluences between the real and the fictional that we focus our object of analysis.
\end{abstract}

\footnotetext{
${ }^{1}$ Acadêmicos do curso de Letras Português/Inglês na Universidade de Santa Cruz do Sul.

2 Docente do Departamento de Letras na Universidade de Santa Cruz do Sul.
} 


\section{INTRODUÇÃO}

0 projeto Vozes da cultura contemporânea 2: o narrador na cultura da conexão, ao qual este trabalho se vincula, tem como intuito analisar a produção ficcional contemporânea, a fim de encontrar tendências que se relacionem a novas práticas de leitura e escrita, hoje bastante relacionadas ao uso da internet. Para tanto, o projeto também se debruça sobre a compreensão de mentalidades contemporâneas.

Quando analisamos o comportamento do sujeito hodierno, pela perspectiva sociológica de Gilles Lipovetsky (2005), visualizamos os perfis virtuais como um palco no qual o sujeito expressa sua própria individualidade, numa sociedade em que "existir" significa relatar-se numa plataforma virtual. Cientes de que a literatura, enquanto forma artística, reflete ou refrata as rotinas sociais, vemos na "escrita de si" uma tendência de ficção contemporânea, influenciada pelas práticas virtuais e o individualismo que elas provocam. Buscamos, portanto, compreender a convergência destas novas práticas de comunicação com as práticas culturais. Na literatura, o resultado desse encontro se revela na narrativa autoficcional, um espaço de "ficção do eu", em que narradores e autores se confundem como personagens protagonistas e no próprio processo de escrita.

Para compreender estes sujeitos autoficcionais, o presente trabalho visa analisar a obra $A$ resistência (2015), de Julián Fuks, vencedora do Prêmio Jabuti na categoria romance e integrante do corpus de pesquisa. Apoiamo-nos em Diana Klinger (2012) para compreender a autoficção como uma "máquina" que produz mitos do escritor, que se revelam no texto quando os relatos de vivência do narrador se assemelham à biografia do autor empírico. Essa estratégia pode surgir através da inserção de biografemas (BARTHES, 1984) ou nos trechos em que o narrador simula o processo de escrita. É neste simulacro, entre mentira e confissão, que Klinger (2012) vê a autoficção como uma performance do próprio autor do texto.

$\mathrm{Na}$ obra em análise, diversos elementos revelam traços autoficcionais e metaficcionais, que podem, a partir do leitor, provocar a relação entre a biografia do autor e o contexto das vivências do narrador. Por exemplo: no enredo, os pais do narrador são psicanalistas argentinos que vieram para o Brasil em busca de uma vida tranquila e um contexto político menos instável; da mesma forma, o autor do texto confirmou em entrevista que seus pais, também psicanalistas, realizaram a mesma trajetória. Fuks ainda nos conta ter entrevistado seus pais e inserido as entrevistas na ficção. Embora essa relação não esteja presente no romance, os paratextos que circulam na internet constroem a relação autoficcional.

Há também um jogo performático, através do qual o narrador-protagonista assume estar escrevendo um livro, encenando seu processo de escritura para aquele que o lê. 0 embate emocional familiar em decorrência da adoção do irmão adotivo, a confissão do próprio autor sobre a introdução de fatos reais no livro e a performance da escritura evidenciam uma conexão intrínseca entre a vida 
de Fuks e seu narrador. Neste contexto, A resistência apresenta cicatrizes de um período histórico em uma conjuntura conturbada que, assim como o narrador, o autor também carrega. Nessas intersecções entre o real e o ficcional presentes em sua escrita é que focalizamos o nosso objeto de análise.

\section{MUNDO CONTEMPORÂNEO: NOVAS MENTALIDADES E AUTOFICÇÃO}

\subsection{Novas mentalidades contemporâneas}

É possível afirmar que, com o advento da internet, nos anos 90 do século passado, diferentes esferas da vida humana se alteraram. Tecnologias em rede e novas práticas que com elas advieram modificaram atividades cotidianas, encurtaram distâncias, produziram novos hábitos, e, assim, transformaram a cultura, em sentido amplo. A mudança se torna fácil de se observar, por exemplo, na fotografia, recurso no qual a nossa relação com essas tecnologias em rede evidenciam sua potencialidade. Se outrora os processos fotográfico e de revelação de foto eram demorados, hoje, em questão de segundos, já ligamos a câmera do celular e compartilhamos a fotografia em tempo quase real - isso quando não realizamos as populares lives, em que o conteúdo filmado é realmente exibido ao vivo. 0 celular, assim, se torna uma extensão da vida, conectado ao nosso público.

Dado o exemplo da fotografia, podemos avaliar como nossos comportamentos e mentalidades se alteraram com os avanços tecnológicos e o surgimento da internet. De uma forma ou outra, essas práticas comunicacionais têm um fator relevante em comum: oferecem a possibilidade de o sujeito falar sobre si mesmo para os outros, numa plataforma digital que se transforma numa plateia virtual. Tal característica se evidencia na popularidade das redes sociais que surgem no avanço dessas tecnologias. Um sujeito pode, atualmente, publicizar desde o seu café da manhã ao seu jantar. Pode tornar pública sua visão ou perspectiva em qualquer formato fotográfico, audiovisual, textual, áudio, etc. Ou pode, então, fazer check-in para mostrar aos seus seguidores virtuais o local em que está no momento. 0 indivíduo contemporâneo, dessa forma, coloca-se numa esfera virtual pública, através da qual relata a si mesmo, sua vida ou cotidiano, para os demais perfis com quem interage. Entretanto, o compartilhamento de sua "realidade" é moldado, e figurações, como personagens de nós mesmos, são construídos - ninguém é, de fato, a pessoa que demonstra ser no seu Instagram, visto que selecionamos, editamos, alteramos, adicionamos filtros, entre outros, ao conteúdo que compartilhamos. Dessa forma, estamos sempre fazendo ficções de nós mesmos. A ficção de nós mesmos que já produzimos em nossas relações cotidianas é potencializada em grau e em assistência pela tecnologia.

Discutindo essa mesma relação entre a literatura brasileira contemporânea e a ficção das redes sociais, Taíssi Cardoso da Silva e Ana Cláudia Munari Domingos (2015) analisam essa 
produção de simulacro dos perfis sociais no mundo contemporâneo, quando vivemos a extrapolação das mídias digitais, das redes sociais, da comunicação virtual e da hiper-realidade. Nesse ciberespaço, o sujeito tem cada vez mais possibilidades de se reinventar, de se recriar numa identidade que difere da própria. Assim, a própria noção de realidade se torna confusa quando é possível optar entre as experiências humanas e as experiências que Katherine Hayles (1999 apud SILVA; DOMINGOS, 2015, p. 3) definiu como pós-humanas. Para Hayles, independentemente da identificação que damos aos significantes que são exibidos na tela de um computador, assim que olhamos para eles, nossa experiência e nós mesmos já nos tornamos pós-humanos.

A imagem de Narciso surge entre os sociólogos para explicar o sujeito contemporâneo. Conforme Cristopher Lasch (1990), a cultura contemporânea exibe traços narcisistas de uma sociedade que busca a realização da individualidade. Este comportamento é definido pelo autor como um "eu mínimo" que, em sua insegurança, tenta reconstruir o mundo à sua própria imagem ao mesmo tempo em que precisa e almeja se fundir numa união com outros - o que parece ser um resumo do comportamento virtual já aqui descrito. Assim, Lasch relaciona a cultura do Narciso com uma preocupação do indivíduo pós-moderno por sua própria sobrevivência psíquica, pelo equilíbrio emocional. Ao considerar que vivemos em uma época carregada de problemas, em uma vida cotidiana que "passa a ser um exercício de sobrevivência" (LASCH, 1990, p. 9), Lasch afirma que o indivíduo sente medo de olhar para o passado e se entregar à nostalgia, ao mesmo tempo em que vive inseguro diante das incertezas do futuro. A saída do indivíduo é voltar-se a si próprio, refugiar-se ao transformar-se em Narciso, ou seja, construindo o mundo à sua própria imagem.

Esse Narciso dialoga com o hipernarcisismo apontado por Lipovetsky (2004). Para o autor, o indivíduo vive inquieto e assustado, no medo do que está por vir. Imerso na era do hiperconsumo e da hipermodernidade, sua psique é atacada enquanto despencam os discursos ideológicos das grandes estruturas tradicionais. Instaura-se uma lógica de moda e consumo, na qual a vida individual e social se voltam à comercialização dos modos de vida. Para Lipovetsky, o medo e a incerteza que cercam o futuro podem obrigar o sujeito a centrar-se no presente, mas tal comportamento resulta numa apatia ao mundo. Lipovetsky dialoga com Lasch ao encarar a exposição excessiva de informações a que os canais midiáticos submetem o sujeito como uma resposta para essa apatia. 0 autor avalia que a oscilação constante de imagens e a velocidade com que essas novas informações são substituídas pela mídia impedem que algum "apego" ou "emoção duradoura" persista no indivíduo. Na fluidez de nossos tempos, as mídias colaboram para acompanhar a velocidade dos acontecimentos.

Assim, Lasch vê a individualidade do eu mínimo como uma resposta a essas transformações sociais, do mundo de objetos duráveis para um bombardeamento de imagens oscilantes. Realidade e fantasia tornam-se, portanto, difíceis de se distinguir e a relação do sujeito com a realidade empírica se torna distorcida. Sem conseguir definir o que é realidade e o que não é, reside no ato 
narcísico a centralidade do real. Impossibilitado de compreender a velocidade do mundo externo, o sujeito volta-se para si mesmo.

É nesse ponto que os perfis virtuais surgem como um local onde essa mentalidade se manifesta. 0 comportamento simulado que o indivíduo parece desenvolver surge como uma resposta a essa mentalidade contemporânea. Não sendo possível tocar o real, o sujeito cria o mundo a partir de sua perspectiva enquanto se dirige a uma plateia de espectadores virtuais.

Diante dessa mudança social, acreditamos que os mais diversos setores da vida humana foram transformados a partir do surgimento da internet. Quando voltamos nosso olhar para a produção cultural, já é possível observar que as narrativas em primeira pessoa se tornam frequentes, demonstrando um novo interesse pela ficção do eu.

\subsection{A autoficção como resposta}

Com o advento da internet houve, na cultura midiática, uma explosão de narrativas vivenciais. Os sucessos se destinaram a biografias, testemunhos, blogs, entrevistas, demais registros biográficos (como os próprios reality shows). Mais recentemente, surgiram os sucessores dos blogs: redes sociais (Instagram, Twitter, Facebook, etc). Isto é, diferentes meios pelos quais é possível produzir discursos do eu. Essas diferentes formas de criar um "eu", porque são parciais, fragmentados, inventados - fictícios - e ainda direcionados a leitores/espectadores e ao efeito que neles produzem, trazem reflexos na arte literária contemporânea, na tendência das escritas de si. E, entre as escritas de si, surge, como resposta à demanda dessa realidade, a autoficção. Certamente não é de hoje que a literatura responde ao cenário da sociedade que a compõe.

Entre as formas de "ficção do eu", a autoficção se revela como uma encenação do autor, aquele que assina o texto. É dessa forma que ela responde à demanda do real, pois traz na ficção alguém (o autor) que é constituído nele, carregado de uma autenticidade que propositalmente confunde o seu leitor, visto que o leitor de romances não espera que a ficção produza essa relação direta com o real. Por isso - como assinala Beatriz Sarlo (1995, p. 11) -, se nós, os leitores, ainda nos interessamos pelos escritores, é porque "não fomos convencidos nem pela teoria nem por nossa experiência, de que a ficção seja, sempre e antes de tudo, um apagamento completo da vida" (KLINGER, 2008, p. 18).

Para Klinger, a autoficção é como uma "máquina produtora de mitos do escritor" (KLINGER, 2008, p. 23). A autora identifica duas maneiras pelas quais a estratégia autoficional se mostra no texto: primeiro, em passagens nas quais a voz do narrador e a do autor se confundem entre relatos de vivências ancorados em referentes reais; e, em segundo, nos trechos em que o processo de escrita se torna "visível" - fazendo surgir alguém que não apenas narra, mas um ser consciente desse processo. 
A autora considera que o relato autobiográfico pressupõe uma subjetividade e uma verdade que são anteriores ao próprio texto e que tal relação é reconhecida pelo leitor. Entretanto, quando o relato simula ser autobiográfico, mas na ficha catalográfica consta ficção, há uma nova relação que se apresenta ao leitor. A narrativa autoficcional coloca em suspeição o que é "mentira" e o que é “confissão".

A figura do autor surge no texto autoficcional através da inserção de biografemas elementos que garantem a matéria biográfica ao fazerem referência ao factual, ou seja, a instantâneos documentais da vida do autor. Conforme Roland Barthes, "a fotografia tem com a história a mesma relação que o biografema com a biografia" (1984, p. 51). Aqui entendemos os biografemas como uma espécie de fotografia "do real" inserida na escrita. Ela provém da memória do sujeito empírico, aquele a ser biografado - o autor - mas produzem, entretanto, um discurso ficcional, confundindo o leitor que pode, ou não, buscar esses referentes do real e interpretar como autoficção.

O texto autoficcional se torna uma armadilha para aquele que lê, pois não há um pacto autobiográfico que se estabelece, mas um pacto oxímoro (JACCOMARD, 1993 apud FAEDRICH, 2015), não existe um sujeito prévio a ser copiado, ou traído, ou seja, "não existe original e cópia, apenas construção simultânea (no texto e na vida) de uma figura teatral - um personagem - que é o autor" (KLINGER, 2008, p. 22).

Klinger entende essa estratégia como performance, definida como a dramatização de um autor através de sua própria escritura. Há um caráter teatral apontado pela autora, pois o autor não se volta para o real, mas para uma encenação. 0 texto se torna o palco, uma dramatização, no qual há um sujeito duplo que se apresenta - o real e o ficcional, o autor e o personagem. Este é o paradoxo teatral que atinge a ficção: quando o ator entra em cena, significa-a ao se desdobrar entre ator e personagem, sendo impossível ser totalmente possuído pelo personagem, da mesma forma que é impossivel representar a si mesmo.

Como texto de ficção, no espetáculo teatral espaço e tempo são ilusórios, no teatro e no romance tudo remete ao imaginário. Quanto mais o ator (ou o autor do texto) entra no personagem, e mais real tenta fazê-lo, mais reforça a ficção, e portanto, a ilusão. Por isso a arte da performance rejeita a ilusão. (KLINGER, 2008, p. 25)

A autoficção pode se revelar, portanto, nos trechos em que o autor simula seu processo de escritura, encenando-o. Esta simulação é definida por Klinger como work in progress, pois dá a impressão ao leitor de estar assistindo "ao vivo" a composição do texto - e, assim, a criação desse sujeito. Num ato performático, é como se o autor subisse ao palco para dramatizar sua escrita diante do público.

$\mathrm{Na}$ literatura brasileira contemporânea, o recurso autoficiconal tem se mostrado uma tendência. Obras como Céu dos suicidas (2012) e Divórcio (2013), de Ricardo Lísias, Ribamar (2011), 
de José Castello, Diário da queda (2011), de Michel Laub, e Quarenta dias (2014), de Maria Valéria Rezende, permitem o encontro dos biografemas de seus autores, além de apresentarem processos de escritura visíveis. Nas obras em que os biografemas não se mostram tão evidentes, é possível notar que a escritura, seu work in progress, é quase sempre presente, aparecendo em obras como Cordilheira (2008), de Daniel Galera, e Galantes memórias e admiráveis aventuras do virtuoso conselheiro Gomes, o Chalaça (1994), de José Roberto Torero.

Assim, após considerações sobre as novas mentalidades contemporâneas e seus respaldos no texto literário autoficcional, buscaremos analisar como A resistência, de Julián Fuks, responde a este quadro apresentado.

\section{AUTOFICÇÃO EM A RESISTÊNCIA}

A aproximação na relação entre leitor e autor, promovida pelas novas plataformas digitais, possibilita, em vários aspectos, os estudos que visamos demonstrar desde o início deste artigo. 0 nosso foco não se volta diretamente para essa aproximação entre o autor e seu leitor, embora essa intimidade nos instigue. 0 direcionamento está na aproximação entre elementos biográficos do autor e a fábula produzida pelo narrador. Julián Fuks é um jovem escritor e critico literário brasileiro que tem se destacado no cenário nacional. Quando eleito pela revista Granta como um dos vinte melhores jovens escritores brasileiros, Fuks teve sua visibilidade intensificada. Em 2016, ganhou o Prêmio Jabuti na categoria romance e foi $2^{\circ}$ colocado do Prêmio Oceanos de Literatura em Língua Portuguesa com A Resistência, obra que integra o corpus de pesquisa e objeto deste artigo.

A partir, sobretudo, das reflexões sobre a escrita do eu, mas ainda compreendendo a literatura na sua própria essência, sabemos que todo processo de escrita, mesmo ficcional, traz elementos do repertório de seu produtor. Quando se escreve um romance (usamos esse exemplo por ser o alvo em questão), escrevemos a partir de nossas experiências, escrevemos sobre o mundo a partir de nosso entendimento sobre ele e assimilamos aquilo que nos é possível assimilar. Partindo desse principio, na autoficção, o "eu" dentro da narrativa vai além: o texto se torna palco e o sujeito desdobra-se entre ator e personagem. A Resistência é um livro de ficção, publicado e premiado como tal, porém, traz elementos biográficos latentes - à espera de sua descoberta -, mostrando uma performance de escrita e construindo, assim, a possibilidade de uma ligação intrínseca entre o narrador personagem e o autor.

Portanto, nessa conexão entre a ficção e o real, os biografemas constituem-se como pilares essenciais para que o autor elabore sua performance no narrador. A fábula tece esses elementos em sua trama que, exposta através da metaficção, conduz o leitor a enxergar a história como uma construção, visualizando esse "eu" que conta e se mostra narrando. Os biografemas constroem na própria ficção uma ponte da fábula com o real e, desse vínculo, nasce um contato natural com o 
presente da narração e, assim, com o contexto imediato em que o leitor está inserido. Dali para os paratextos que trazem elementos tanto críticos quanto biográficos é apenas um deslizar do dedo. Muitas vezes não é preciso exatamente procurar, pois esse tema é recorrente nas redes, onde a presença de artistas é comum. Na leitura de $A$ Resistência buscamos esses vestígios e nos deparamos com uma cadeia de relatos autoficcionais.

A narrativa de A Resistência costura-se em torno de uma família argentina que foge para o Brasil em busca de uma situação política mais confortável para criar seus filhos. Embora não seja o contexto político mais adequado, o Brasil se torna uma opção viável, levando em consideração que o casal era militante ativo contra o regime ditatorial argentino. A narração da história é feita pelo filho mais novo do casal, que busca, através dela, compreender o desacerto de seu irmão adotivo no núcleo familiar. 0 irmão, desde criança, logo que haviam chegado ao Brasil, já demonstrava um distanciamento emocional e uma fuga para algo abstrato aos olhos da família adotiva. Nessa busca, o narrador personagem rememora sua história e reconstrói, a partir de sua escrita, um irmão que ele ainda não conhece, mas que espera compreender, quase como um ato de desculpa, ao mesmo tempo que busca redescobrir, nesse tecido familiar, a sua própria essência.

$A$ resistência tece um leque de elementos que o leitor pode identificar como análogos à vida pessoal do autor, e é para esses biografemas, entendidos como estratégias ficcionais de Fuks, que voltamos nossos olhos. Chamamos atenção, primeiramente, para a profissão de escritor, que liga intimamente o autor e o narrador da obra justamente porque além da coincidência existe um jogo performático do processo da escrita dentro do romance, como demonstram os fragmentos abaixo:

[...] só queria conhecer o apartamento onde viveram porque estou escrevendo um livro a
respeito, e aqui minha voz assume alguma imponência, um orgulho injustificado que tento
esconder, um livro sobre essa criança, meu irmão, sobre dores e vivências de infância, mas
também sobre perseguição e resistência, sobre terror, tortura e desaparecimentos. (FUKS,
2015, p. 58)
Depois, ainda deitado em sua cama, era o livro o que me preocupava. Com sua morte, por
alguma razão o livro não fazia mais sentido, eu teria que abandoná-lo, teria que rasgar todas
estas páginas indecisas, lançá-las nas águas límpidas de algum rio, queimá-las numa lareira
de fogo farto - qualquer imagem vulgar já me bastava. Como se o livro fosse uma longa carta
para ele, uma carta que ele jamais leria (e se o livro for uma longa carta para ele, isso é o que
agora cogito, preciso escrevê-lo melhor, preciso torná-lo mais sincero, mais sensível). (FUKS,
2015, p. 71)

A marcação temporal que evoca uma atividade em construção - "estou escrevendo" - e em prospecção - "e se o livro for" - relaciona essa ação com o processo de escritura presente, aquele que o autor, Fuks, está erigindo e, assim, evocando uma performance desse autor - que não é ele próprio mas também não é apenas um narrador. Fuks quer causar ao seu leitor a sensação de que o texto está se montando diante de seus olhos:

Hoje sonhei com a morte do meu irmão. Digo hoje para deixar cravado no tempo, para me distanciar. Acabo de sonhar com a morte do meu irmão e ainda sinto a latência do sonho a me ocupar, por isso apresso estas palavras subsumido no mal-estar. (FUKS, 2015, p. 69) 
Como se abordasse a seriedade da própria autoficção, o narrador de Fuks problematiza a inserção de dados reais de alguém numa obra de ficção que se apresenta aos seus leitores, sua "plateia":

Não quero, não posso fazer do meu irmão um artista da fome. Não quero descrever um rosto pálido, ou costelas salientes a esgarçar uma cicatriz, como se inventasse um personagem qualquer para um novo livro, na forja de mais um espetáculo assombroso ou triste. Não quero, não posso expô-lo numa jaula cujas barras são estas linhas, para o apreço de uma plateia ansiosa por sentir, por nutrir sua compaixão, alimentar seu altruísmo. (FUKS, 2015, p. 73)

Em diversos momentos a metaficção se faz presente e o narrador discute sua própria obra dando espaço para a performance. "Sei que escrevo meu fracasso. Queria escrever um livro que falasse de adoção" (FUKS, 2015, p. 95). 0 ato performático assume seu ápice quando a voz narrativa finge não poder voltar para apagar o que já foi escrito, como se a sua figura de escritor não conseguisse reescrever o próprio livro, afinal, ele está pronto nas mãos do leitor:

Releio agora a narrativa desse episódio, desse clímax da nossa história, e lamento por um instante ter me esquecido de falar das lágrimas: como se contar quanto chorávamos enquanto meu irmão explodia em verbo pudesse alterar o sentido de tudo, ou pudesse aumentar sua intensidade. (FUKS, 2015, p. 126)

Aos poucos, a performance vai tomando outras proporções: os próprios personagens se inserem como leitores da obra. Discutem a verossimilhança do recurso autoficcional e assumem a falta de "mentira" da obra.

\begin{abstract}
Na noite passada meus pais leram o livro que Ihes enviei, enganaram a insônia com estas páginas, por algum tempo estiveram depurando o que poderiam comentar, como lidariam com esta situação um tanto exótica. É claro que não podem fazer observações meramente literárias, ambos ressalvam como se quisessem se desculpar, durante toda a leitura sentiram uma insólita duplicidade, sentiram-se partidos entre leitores e personagens, oscilaram ao infinito entre história e história. É estranho, minha mãe diz, você diz mãe e eu vejo meu rosto, você diz que eu digo e eu ouço minha voz, mas logo o rosto se transforma e a voz se distorce, logo não me identifico mais. Não sei se essa mulher sou eu, me sinto e não me sinto representada, não sei se esses pais somos nós. Há sempre um matiz triste nos seus escritos, ela insiste e eu noto alguma mágoa. Entendo o apego que você tem pela intensidade, mas não sei se entendo por que ela tem de ser tão melancólica. Você não mente como costumam mentir os escritores, e no entanto a mentira se constrói de qualquer forma; não sei, talvez eu queira apenas me defender com este comentário, mas suspeito que não fomos assim, acho que fomos pais melhores. (FUKS, 2015, p. 134)

Me lembro e não me lembro de muito do que você narra, dos vários episódios ásperos, mas é evidente seu compromisso com a sinceridade, um compromisso que eu não termino de decifrar. Não entendi bem, por outro lado, por que você preferiu inverter o conflito com a comida, subverter o sobrepeso do seu irmão e retratá-lo magro. Apreciei, em todo caso, que houvesse ao menos um desvio patente, vestígio de outros tantos desvios, apreciei que nem tudo respondesse ao real ou tentasse ser seu simulacro." (FUKS, 2015, p.135)
\end{abstract}


As semelhanças entre a estrutura familiar do autor e do narrador da trama, comparadas através dos paratextos - entrevistas, resenhas - são reforçadas pela metaficção, por exemplo: autor e narrador são escritores, os pais de ambos eram psicanalistas argentinos que imigraram para o Brasil e ambos têm um irmão adotivo. Estas pistas biográficas revelam traços autoficcionais, figuram traços do autor no narrador personagem, demonstrando, na prática, a "escrita de si" e assumindo no próprio texto a existência de uma ficção e uma autoficção:

0 parto eu não posso inventar, do parto nada se sabe. Pondero agora, passadas tantas páginas, que deveria ter sido fiel ao impulso de suprimir aqueles pobres cenários imaginários, que deveria ter cedido à hesitação e calado sobre esse acontecimento insondável. Não foi assim, não foi narrável, o nascimento do meu irmão. 0 quarto branco ou o opressivo pavilhão, o som de botas contra o piso ou as mãos doutas em inspeção, basta, já chega, são todas ficções descartáveis, são meras deturpações. (FUKS, 2015, p.59)

Ao 0 Globo (2016), Fuks afirma até mesmo ter entrevistado seus pais e inserido a entrevista no livro, um indício transparente do vínculo entre o autor e o narrador do livro. Em outra situação, Fuks admite ter introduzido no texto ficcional, uma conversa, dele com o irmão, referente à escrita do romance. 0 próprio autor confirma a tese que aqui defendemos: a inserção de dados empíricos para a construção de seu romance.

Isso está narrado no livro, essa passagem que ele me pede para escrever. Quando fui procurálo para dizer que eu pretendia fazer isso, ele já não se lembrava mais. Fui, então, percebendo que, para escrever sobre o meu irmão, era necessário resgatar a história dos meus pais e a relação deles com a ditadura argentina. (FUKS, 2016)

Inserimos aqui a passagem à qual Fuks se refere, o momento em que o irmão adotivo do narrador pede que ele escreva um livro sobre adoção, da mesma forma como foi sugerido pelo irmão do autor.

\begin{abstract}
Vocês não conseguem entender como é. É como uma agulha que alguém vai enfiando na sua veia e parece não ter fim. (...) E enquanto meu irmão batia a palma da mão no antebraço, a pele a cada golpe um pouco mais vermelha, enquanto eu tratava de compreender que agulha era aquela, quem era aquele alguém que Ihe enfiava uma agulha, que substância despejava em sua veia, quem era o outro que Ihe arrancaria o braço com tanta violência, enquanto me empenhava em decifrar tudo aquilo que eu não entendia e jamais seria capaz de entender, meu irmão soltou a frase que não pude esquecer, a frase que me trouxe até aqui: Sobre isso você devia escrever um dia, sobre ser adotado, alguém precisa escrever. (FUKS, 2015, p. 124)
\end{abstract}

Para finalizar, Fuks se une ao seu narrador ao ser entrevistado pela Revista Cult Online. 0 autor é questionado com uma pergunta que vincula a voz narrativa em primeira pessoa com a voz dele próprio, através da pergunta: "Além de tentar encontrar algo das raízes familiares do seu irmão, você também tenta se reencontrar ao longo do livro. Pode falar um pouco sobre essa busca?" (CULT, 2016). Assumindo essa colagem, Fuks responde como se fosse o próprio narrador: "Na verdade a minha relação com a Argentina sempre foi muito ambivalente e complicada. Eu sempre tive muita 
identificação com a Argentina e procurei ao máximo me aproximar do país, mas ao mesmo tempo encontrava limites nessa cumplicidade" (CULT, 2016).

\section{CONSIDERAÇÕES FINAIS}

Como sujeitos integrados nessa sociedade cada vez mais mediada pelas redes sociais, também representamos, como leitores, uma parcela dessa possível tendência. Assim, respondendo aos anseios do sujeito narcisista, a autoficção se mostra exitosa em seu efeito de ilusão apenas quando o leitor faz esse entrelaçamento entre a presença de biografemas do autor e elementos da fábula: mesmo sem a exigência do pacto autobiográfico, o leitor reconhece aquele que fala a partir dessa performance, desse espelhamento de um narciso. 0 autor contemporâneo pode brincar com o leitor, confundindo realidade e verossimilhança, inventando sua própria autobiografia. Mas, aquele que lê, se aceita esse novo pacto, o faz atento e interessado no autor que escreve, pois nem um, nem outro, convence-se de que a ficção é "um apagamento da vida" (SARLO apud KLINGER, 2008). Neste espetáculo, é preciso que o texto que se utiliza do recurso autoficcional seja lido como um show e que isso seja entendido também como estratégia do fictício, ou seja, também como um elemento estético. 0 leitor torna-se ativo, a plateia interage.

Na leitura da obra de Fuks, compreendemos a performance como uma resposta artística a esse cenário virtual contemporâneo, mas também a muito antiga necessidade de narrar como forma de ser e estar no mundo, entender-se, construir-se como sujeito. Embora esteja visível para nós, pesquisadores, essa possibilidade de uma nova tendência literária que se volta para as escritas do eu, é ao leitor que cabe tecer as analogias que transformam a ficção em autoficção, seguindo as pistas desse autor performático. Ao apropriar-se do recurso autoficcional com maestria, Julián Fuks faz o drama acontecer no palco da página. A narrativa se apresenta ao leitor numa construção em presença, enquanto a voz que narra se mescla à de seu autor - ambos figurados em um mesmo sujeito sob os olhos do leitor. Fuks sobe ao palco, veste-se de narrador e começa a escrever sua obra.

\section{REFERÊNCIAS}

BARTHES, Roland. Câmara clara. Trad. Júlio Castañon Guimarães. Rio de Janeiro: Nova Fronteira: 1984.

FUKS, Júlian. A resistência. São Paulo: Companhia das Letras, 2015.

O GLOBO. 'A resistência' consagra curta trajetória de Julián Fuks como escritor. Entrevistador: Alessandro Giannini. [10 dez. 2016] Rio de Janeiro: 0 Globo, 2016. Entrevista concedida ao 0 Globo por Julián Fuks. Ilustrada online. Disponível em: https://oglobo.globo.com/cultura/livros/aresistencia-consagra-curta-trajetoria-de-julian-fuks-como-escritor-20620415\#ixzz4IEjgLKUg Acesso em: 20 mar. 2018.

CULT. "O Brasil é incapaz de refletir sobre seu passado", diz Julián Fuks. Entrevistadora: Paula Pires. [2016] São Paulo: Revista Cult, 2016. Entrevista concedida à Revista Cult por Julián Fuks. Ilustrada online. Disponivel em: https://revistacult.uol.com.br/home/o-brasil-e-incapaz-de-refletir-sobre-seupassado-diz-julian-fuks/ Acesso em: 20 mar. 2018. 
KLINGER, Diana. Escritas de si, escritas do outro: o retorno do autor e a virada etnográfica. Rio de Janeiro:

KLINGER, Diana. Escrita de si como performance. Revista Brasileira de Literatura Comparada. São Paulo, $\quad$ n. 12, $11-30, \quad 2008 . \quad$ Disponível em: http://www.abralic.org.br/downloads/revistas/1415542249.pdf. Acesso em: 14 mar. 2018.

LASCH, Christopher. 0 mínimo eu: sobrevivência em tempos difíceis. Trad. João Roberto Martins Filho. São Paulo: Brasiliense, 1990.

LIPOVETSKY, Gilles. A era do vazio: ensaios sobre o individualismo contemporâneo. Trad. Therezinha Monteiro Deutsch. Barueri: Manole, 2005.

LIPOVETSKY, Gilles; CHARLES, Sébastien. Os tempos hipermodernos. Trad. Mário Vilela. São Paulo: Barcarolla, 2004.

SILVA, Taíssi A. Cardoso da; DOMINGOS, Ana Cláudia Munari. Reflexos do eu: simulação e narcisismo na literatura contemporânea de autoficção. Anais do XXXVIII Congresso Brasileiro de Ciências da Comunicação, Rio de Janeiro, 4 a 7 de setembro de 2015 . Disponível em: http://portalintercom.org.br/anais/nacional2015/resumos/R10-2558-1.pdf. Acesso em: 9 mar. 2017. 